\title{
The Effects of Wastewater from Shrimp Farm in South Qeshm
}

\author{
Mehdi Karimi ${ }^{1}$, Farhad Darabinia ${ }^{2}$ \\ ${ }^{1}$ Senior Engineer, Fara Darya Arsheh, Co., mehdikarimi@live.com \\ ${ }^{2}$ Managing Director, Fara Darya Arsheh, Co. $\underline{\text { f.darabi@faradarya.co.ir }}$
}

\begin{abstract}
Released effluents containing high levels of pathogenic and non-pathogenic microorganism enhanced coastal aquatic mortality. A shrimp farm is going to be constructed in the southern coast of Qeshm Island. The reviews represent that the initial design of inlet and outlet does not meet minimum requirements for coastal water quality parameters. In this study, we defined three options, one initial design and two newly proposed, in order to investigate the concentration of pollution in coastal area using numerical models. Two new breakwaters constructed in the area decreased coastal current significantly, therefore, the initial design failed to meet water quality standards and need to be modified. The third proposed scenario was selected as the best option for intake and outtake locations.
\end{abstract}

\section{Introduction}

The shrimp industry, by releasing effluents containing high levels of pathogenic and non-pathogenic microorganisms, is effective on coastal aquatic mortality and has an undeniable role in spreading aquatic pathogens, [1]. In these conditions, fish farms can act as a hub for pollution and invade other environments, including other neighboring farms, and cause numerous health and economic problems in the area of emission, [2]. Therefore, special attention should be considered in determining the effluent outlet of these farms.

Entering wastewater effluents into the shallow environment and settling pollutants and heavy metals have adverse effects on the environment, [3\&4]. In addition, a long life of pollutants impedes the use of water for adjacent areas. Experts therefore strongly recommend controlling and purifying the effluent and releasing it to high-speed seawater to dilute the contaminants rapidly.

Morvarid Company is building a shrimp farm in an area of 150 acres and needs a water inlet and an effluent outlet to effectively operate the shrimp farm. According to a 
design by Morvarid Company, the effluent discharges into the shallow water area after crossing under the Microalgae Company lands. The initial investigations showed that the designated site for effluent discharge is not suitable at all, and in addition to the severe contamination in adjacent land, the Microalgae company will have many problems due to being located in a shallow and low flow area. With the completion of the harbor breakwater offshore, the flow rate will be much slower and longer. Consequently, the current designated output location must be changed.

In this paper, a comprehensive wave and hydrodynamic modeling were performed to track the effluent discharge and contaminants in the area and review the impacts of pollution on the adjacent area.

\section{Method}

In order to investigate the effects of effluent from shrimp farming activity on the ground of Morvarid Company, due to the progress of the construction of port breakers, the port structures have been considered in the investigation scenarios, Figure 1.

Simulation of wave and flow patterns in the design area, using the transmission model of the Mike21 FM SW and FM, were performed. The effluent diffusion pattern is investigated in the following scenarios:

- Scenario 1: Output at point 1

- Scenario 2: Output at point 2

- Scenario 3: Shifting output and input locations, exit from point 3 and inlet from west of breakwater, Figure 1.

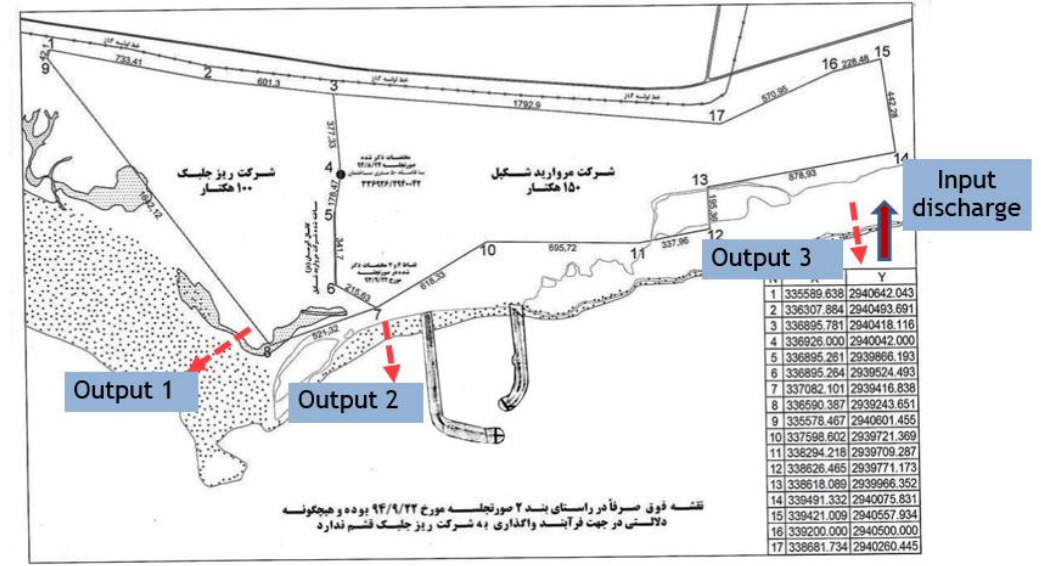

Figure 1. Locations of Morvarid Company farms and proposed locations for input and output discharges

The MIKE21 SW-HD model has the ability to simulate coastal parameters on a flexible grid that is used in studies of different ranges. In studies of wave, flow and 
transport phenomena and their effects on the coastal and marine environment, numerical models with the capability of solving equations on the unstructured grid are remarkable. Therefore, MIKE21 SW is used for modeling waves and MIKE21 HD is used for simulation of current and transport. The ability and accuracy of these models are verified in different studies, [5 \& 6].

For the open boundary of the model, we implemented wave, water level, and current data from Monitoring and Modeling Studies of Hormozgan Province project, [7 \& 8 \& 9].

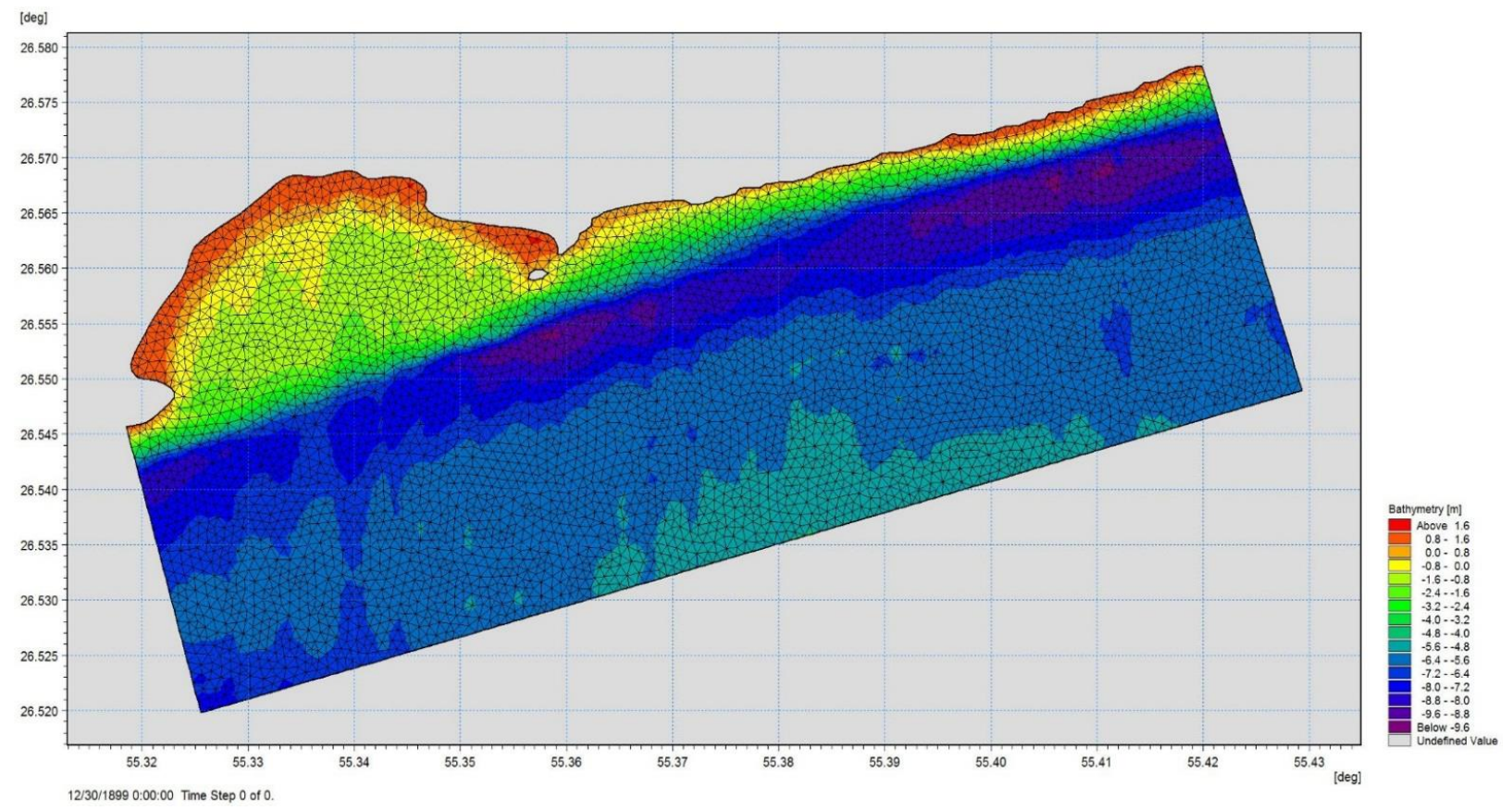

Figure 2. Unstructured grid used in this project

\section{Results}

The results of measurements of the amount of water released from the merged canals out of the shrimp farm show an average discharge of $2 \mathrm{~m}^{3} / \mathrm{s}$. The discharge rate of the outlet channel of the Helle Shrimp Farm in Bushehr Province and the Govatr Shrimp Complex is 0.5 to $6 \mathrm{~m}^{3} / \mathrm{s}$. In this simulation, along with the hydrodynamic model, the transport model is assumed to have an output of 2 cubic meters at an initial concentration of $100 \mathrm{~g} / \mathrm{L}$ for different scenarios. The model was validated by measurements in the region. As shown in Figure 3, the model is correlated well with the measurements in the region, Figure 3. 


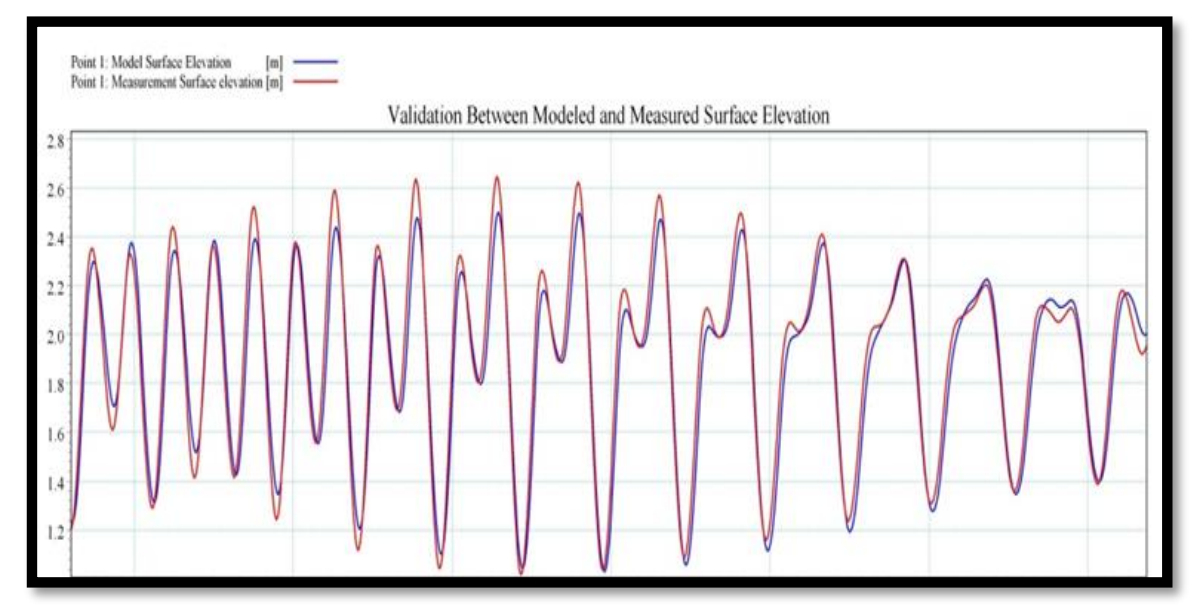

Figure 3 Validation of the model with measurements

According to the simulation results of the flow and transportation model, the flow velocity status at outlet No. 1 is further reduced by the completion of the port breakwater construction operation, thereby increasing the concentration of pollutants in that range, Figure 4. As a result, the worst option for placing the effluent outlet was this option and did not meet the environmental criteria and had to be displaced.

Figure 5 shows the results of the simulation for the concentration of pollution for the second, left, and third, right, scenarios. As can be seen, the third scenario is the best and the pollution diffused much more than other scenarios.

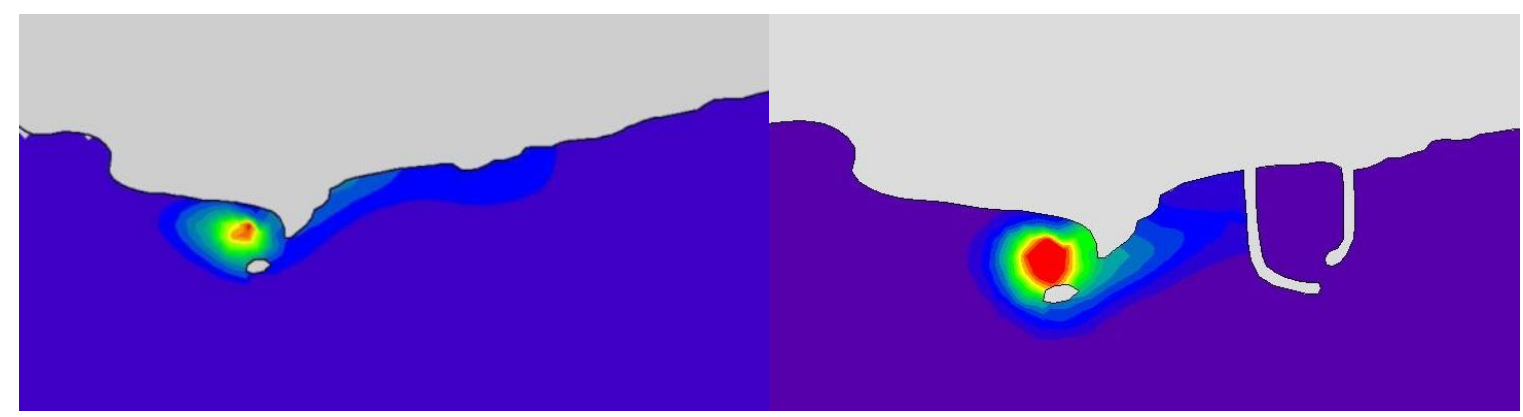

Figure 4 The concentration of pollution before and after the construction of the breakwaters. Construction of breakwater decreases current and wave intensity led to more concentration of pollution 

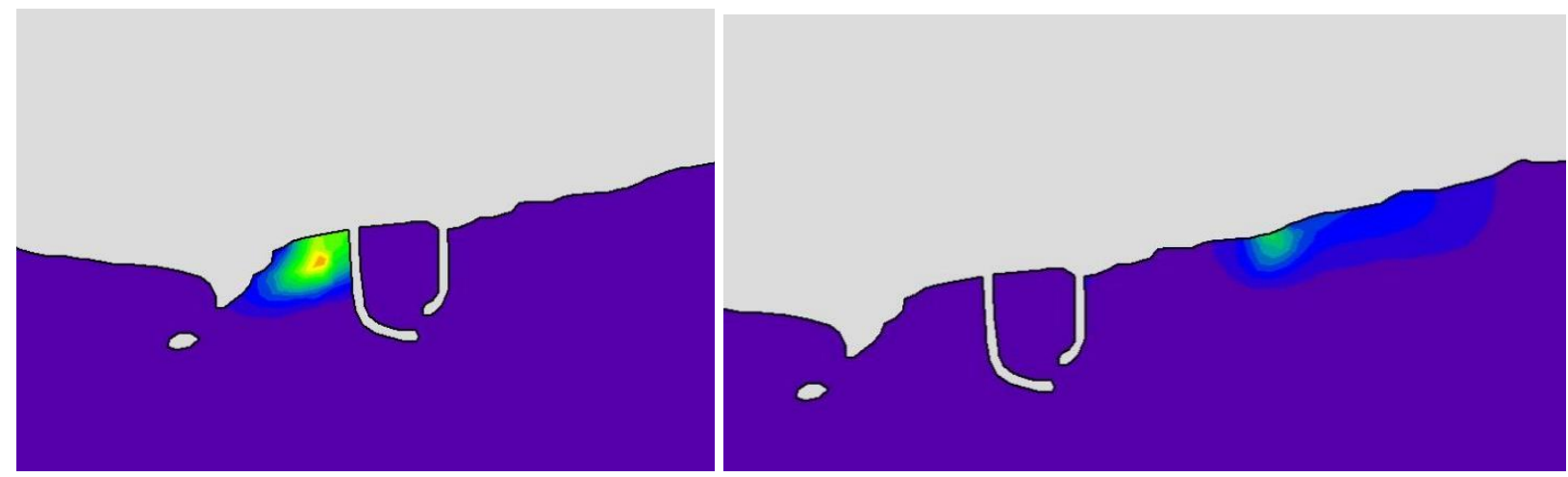

Figure 5 Distribution of pollution for second and third scenarios, The third scenario is considered the best option

\section{Conclusions}

Based on the results of the simulations in this study, we can conclude Scenario 1 (at the bottom of the Microalgae refinery's landfill) leaves the highest pollution concentration in the marine environment and will increase the residence time. Due to the relative disruption of the current by the breaker, in all options, the outlet will have very little impact on the inlet. In all cases where the outlet is located to the west of the port, the output concentration is over $20 \%$ and does not fall within the permissible range of environmental standards.

Only when the effluent concentration is below $10 \%$ (permissible in accordance with environmental criteria) if the output is selected to the east of the port. According to the results, wastewater discharge from location \#1 (from within the Microalgae into the shallow tidal zone) is the worst possible option and should be relocated due to adverse environmental impacts.

After evaluating the simulation results of the investigated options for selecting the output location, the best option for deploying the output is Option 3 (beginning of the Morvarid Company domains). By selecting water inputs from the west of the port, better water quality will be achieved for shrimp breeding. 


\section{References}

[1] Pham, D., Ansquer, D., Chevalier, A., Dauga, C., Peyramale, A., Wabete, N., \& Labreuche, Y. (2014). Selection and characterization of potential probiotic bacteria for Litopenaeus stylirostris shrimp hatcheries in New Caledonia. Aquaculture, 432, 475-482.

[2] Ferreira CS, Nunes BA, Henriques-Almeida JM, Guilhermino L (2007) Acute toxicity of oxytetracycline and florfenicol to the microalgae Tetraselmis chuii and to the crustacean Artemia parthenogenetic. Ecotoxicol Environ Saf 67:452-458

[3] Samuelsen BO, Lunestad BT, Ervik A, Fjelde S (1994) Stability of antibacterial agents in an artificial marine aquaculture sediment studies under laboratory conditions. Aquaculture 126:283-290

[4] Andreozzi R, Raffaele M, Nicklas P (2003) Pharmaceuticals in STP effluents and their solar photodegradation in aquatic environment. Chemosphere 50:1319-1330

[5] Fonseca, R.B.; Gonçalves, M.; Guedes Soares, C. Comparing the Performance of Spectral Wave Models for Coastal Areas. J. Coast. Res. 2017, 33, 331-346, doi:10.2112/JCOASTRES-D-1500200.1.

[6] Ilia, A., \& O'Donnell, J. (2018). An Assessment of Two Models of Wave Propagation in an Estuary Protected by Breakwaters. Journal of Marine Science and Engineering, 6(4), 145. MDPI AG. Retrieved from http://dx.doi.org/10.3390/jmse6040145.

[7] Rafipour Langeroudi, M., Ilia, A., Darabinia, F., Allahyar., M. R., (2012) Study of Design Water Level Elevations in Hotspots of Hormozgan Coastline, 10th International Conference on Coasts, Ports and Marine Structures (ICOPMAS), Tehran, Iran.

[8] Mazaheri, S., Golshani, A. and Darabinia, F., (1998) Applications of mathematical models in diffraction analysis and designing harbor layout of the South Pars Gas Field in the Persian Gulf, 3rd International Conference on Coasts, Ports and Marine Structures (ICOPMAS), Bandar Abbas, Iran.

[9] Ilia, A., Mazaheri, S., Allahyar, M. R., (2010) Comparison of statistical (Q-Q plot) and classical calibration methods in wave modeling, 9 th International Conference on Coasts, Ports and Marine Structures (ICOPMAS), Tehran, Iran. 